\title{
Perceived Educational Knowledge Differences Among Airport Managers and Entry-level Airport Operations Employees
}

\author{
Stephen M. Quilty \\ Bowling Green State University
}

\begin{abstract}
Airport managers, supervisors, and operations personnel at various airports throughout the United States were surveyed to assess the knowledge and skill requirements necessary for airfield operations personnel. They were then asked to assess the degree to which recent college graduates of aviation programs or new hires met the desired requirements. This paper presents findings comparing the two assessments and discusses the differences between desired knowledge and actual knowledge of new hires. Results of the study have implications for university and college aviation programs that offer aviation or airport management curricula as well as for airport organizations.
\end{abstract}

\section{INTRODUCTION}

Identifying or determining the content of a particular educational course is a necessary challenge for those engaged in curriculum development. In the aviation field, flight curriculum and course content has been well developed through academic and government cooperation, study, and evaluation. Less developed is curriculum study related to aviation management and, in particular, to airport management.

While accrediting bodies such as Aviation Accreditation Board International (AABI) (formerly the Council on Aviation Accreditation (CAA)), National Association of Industrial Technology (NAIT) and American Assembly of Collegiate Schools of Business (AACSB) call for industry advisory boards to provide feedback on respective university programs about their relevancy, the boards generally are not able to provide substantive data to support aviation or airport management content and course suggestions. Instead, the industry boards generally provide anecdotal information based upon the experience and involvement of their members. Phillips (2004), writing about the difficulty in assessing or comparing courses within aviation management programs, sums it up this way: "Judgments about specific course content based on title and catalog descriptions is an inexact science (page 41)." Both Phillips (2004) and Quilty (2004) called for better delineation of the content to be taught within a particular aviation management specialization.
Attempting to address that inexact science, Quilty (2005) undertook a study that identified the knowledge and skill requirements deemed important for entry level airport operations employees. A goal of the study was to assist in the development of curricula for an airport management related program. Kaps and NewMyer (2001) had previously surveyed state aeronautic agencies about published handbooks for airport managers. They then analyzed the content of the available handbooks and compared it to industry training devices for the content covered. Kaps and NewMyer sought information on general aviation airports, while Quilty's study encompassed both general aviation and air carrier airport knowledge requirements.

This paper further contributes to the aviation and airport management field by identifying knowledge and topic areas deemed important by airport managers, supervisors, and operations personnel at various-sized airports, and it explains how such knowledge and topic areas differ from what new hires are thought to actually possess. The study results reported in this paper can be used to better identify learning outcomes as well as to delineate course content in an aviation management degree program that will better address the preparation of individuals for entry-level positions at airports.

\section{METHODOLOGY}

The survey instrument used in the study was targeted toward individuals whose job positions are related to the safe operation of an airfield, such as airfield operation, maintenance 
and inspection personnel. Surveyed for this study were individuals who had responsibility for hiring or supervising airfield operations employees, and individuals employed in airfield operations positions. The study specifically targeted airfield operations rather than terminal or landside operations. Airfield operations is an area of qualification concern for the Federal Aviation Administration (FAA) in light of changes to Part 139 (Certification of Airports), 14 Code of Federal Regulations (CFR).

The survey instrument was developed by identifying 91 knowledge variables derived from Part 139; analyzing job descriptions used in Quilty's (2004) study; the CAA Accreditation Standards Manual (CAA, 2003); Flouris and Gibson's (2002) survey instrument, curricular material from various university aviation programs, and a similar knowledge list developed for the National Business Aviation Association (NBAA) Corporate Aviation Management Development Committee (Quilty, 1996). The survey was approved for use by the Human Subject Review Board at Bowling Green State University, and it was pretested among members of the American Association of Airport Executives (AAAE) Airport Training Committee.

Data were collected from large-hub, medium-hub, small-hub, non-hub and general aviation airport operators. The airport categories are identified by the FAA National Plan of Integrated Airport System (NPIAS). The hub designation relates to the number of operations and passenger enplanements an airport has during a calendar year. The 2003 NPIAS lists 31 large-hub airports, 37 medium-hub airports, 68 small-hub airports, 247 non-hub airports, and 2,961 other airports (other commercial service,

Table 1. Instructions given to survey respondents.

In the LEFT Column, identify how important the topic is to an airfield operations person based on the numbers 1 through 6 below

1 - EXTREMELY IMPORTANT

2 - VERY IMPORTANT

3 - SOMEWHAT IMPORTANT

4 - NOT VERY IMPORTANT

5 - NOT AT ALL IMPORTANT

6 - DO NOT KNOW IMPORTANCE reliever, general aviation) (U.S. Department of Transportation, 2004, pg. 5).

An initial electronic mailing of the survey was made in July, 2004, to 356 individuals who were identified in the 2003 membership directory of AAAE. The individuals were identified by their job titles and airport size as those likely to have direct supervision of new airfield operation hires or would have responsibility for hiring them. Of the initial mailing, 82 e-mail addresses were returned undeliverable and 274 e-mails were successfully transmitted. Two follow up e-mails requested responses in August of 2004. Receipt of surveys was stopped in late September. Of the 274 valid e-mails delivered, usable responses for this comparison study range between 100 and 106 (36.5 to 38.7 percent) because of the requirement for responses to be matched pairs from two columns. Not all respondents completed both columns.

Demographic information collected for this study allowed for determination of the respondent's position and title; whether the respondent was in a supervisory position or an entry-level position; and the size of the airport. The demographics provide a cross section of the airport organizations for 106 responses; 19 were from large-hub airports, 19 from medium-hub airports, 16 from small-hub airports, 26 from non-hub airports, and 26 from general aviation/reliever airports. However, the results of this study are reported in aggregate rather than broken into the various airport hub sizes because the nature of an entry-level position at any airport requires the same basic knowledge and skills for consideration and therefore can be combined.

In the RIGHT COLUMN, identify how prepared you feel operations new hires or applicants are using the scale A through E below.
A - WELL PREPARED
B - ADEQUATELY PREPARED
C - SOMEWHAT PREPARED
D - LESS THAN PREPARED
E - NOT AT ALL PREPARED 
The survey requested Likert-type responses in two columns. The survey asked individuals employed in airport management and operation positions in the United States their perception of those knowledge requirements deemed important for individuals employed in the field of airfield operations, or for those individuals having duties to inspect or ensure the safety of the airfield. It further asked them to rank the level of knowledge they believed new hires or recent applicants actually possessed relative to the topic areas. Participants in the study were given the instructions shown in Table 1.

\section{RESULTS}

An analysis of variance was performed for each of the 91 variables in both columns. A standard matched pair $t$-test procedure was then performed to analyze the mean of the differences (Left column minus Right column) between the two responses. Statistical analysis was accomplished by the Bowling Green State University using SAS programming. The results are reported in Appendix A.

The first column, titled "Rank," identifies the aggregate ranking of importance of the topic variable ( 1 is highest) as reported by Quilty (2005) in his study. The number ( $n$ ) of valid responses used for comparison, the mean $(M)$ of the differences and the standard deviation $(S D)$ are identified. $T$-test values $(t)$ are reported, followed by the determination of significance $(p)$. The degree of significance between the means comparison is for values of $p>0.05$. The identifier $\mathrm{L}$ indicates the left column is significantly greater than the right column. The identifier $\mathrm{R}$ indicates the right column is significantly greater than the left column. ND indicates no significant difference exists between the means of the left and right columns.

\section{DISCUSSION}

In his 2004 paper, Quilty asked. "What courses should make up the core of an aviation management program?” The Council on Aviation Accreditation (CAA) Standards Manual identifies the object of an aviation core is to ensure that all students in a collegiate aviation program have a foundation of essential and specialized knowledge of national and international aviation and aerospace systems appropriate to the degree being sought. The students' foundation of knowledge of these systems should include a broad understanding of the components of the systems, insight into how these components function together, and an understanding of how these relate to the physical, economic, political and social environments within which these systems operate (CAA, 2003, pg. 12).

The results of the current study indicate that individuals entering airport operations do not have this foundation and that a more specialized understanding of the components should be achieved. Although not all new hires will have college degrees or an aviation management background (hence, would not have been exposed to a foundation of knowledge), Quilty's review (2004) of airport operations' job descriptions identified that most position announcements required either a 4-year degree or previous aviation experience for consideration.

There are a number of factors that may skew the differences between what is required and whether new hires meet the requirements. The hiring practice, pay scale, or location of some airports may preclude consideration of well-qualified individuals, resulting in an employment pool lacking in the identified knowledge areas. Larger airports with specialized departments or higher level of responsibilities for their operations personnel may require years of experience as a prerequisite. Some of the responses may have been regionally specific thereby skewing the means (i.e., prevalence of snow operations, wildlife, etc.). Three individuals indicated no new employees had been hired during the past five years so it was difficult to assess new hires (they did not fill out the second column and hence that data was not used).

Still, the most striking aspect of the results is the general indication that airport managers and supervisors believe new hires do not have the requisite knowledge. The data indicate that of the 91 knowledge variables, new hires were less than prepared in 74 of them. Further analysis shows that those 74 knowledge variables ranked within the top 77 of those topics ranked by Quilty's 2005 study. Courses typically recognized in a management core (i.e., 
macro- and microeconomics, socioeconomics, psychology, computer science, statistics, marketing, and political science) were ranked in the lower 10 percent of the ranking, and the $t$ tests indicate that new hires were viewed as being well versed in those areas. Surprisingly, the topics of international commerce, airport history, and travel and tourism fell in this area as well, topics not normally part of a management core.

For employment in an airfield operations position, airport organizations require a more specific understanding of the components, rather than broad one, based on the reported results. To a large degree, the task of an airport operations position requires the application of knowledge. A review of texts commonly used in a university airport management courses (Quilty, 2004), aviation management courses (Prather, 2006), and the industry (Kaps \& NewMyer, 2001) indicate they cover the requisite knowledge for the most part, but the actual degree of content is not fully explored in the reviews. This paper points to the need to better incorporate specific knowledge and learning outcomes in existing curriculum or to develop a new curriculum that accomplishes that goal.

Appendix B presents comments that were submitted by survey respondents and may help to clarify some of the differences found in the results. The comments contain several themes and point to problems within the industry and aviation education programs. One theme is that more operational content needs to be taught, which is supported by this study. Another theme is the expectation that a new hire in airport operations will generally require up to two years of additional training before being allowed to assume autonomous responsibilities. This theme points to the need for airports to have welldeveloped employee orientation or training programs. The counter to a lengthy training period is the initial personnel inefficiencies incurred and the lack of available money or resources to adequately support the training effort. A third theme mentioned in the comments is for on-the-job (OJT) training or internships. Internships are mentioned as important ways to bridge the gap between acquired knowledge and applied knowledge. However, the counter to the availability of internships is similar to that of a lengthy orientation program: inefficient use of personnel, and the lack of available money, supervision, training, or resources.

One question to be raised by the reported data is how to address the significant differences? Three primary methods are suggested to achieve the goal. One is to better educate and train individuals by revising university and college curriculum content to focus on learning outcomes that meet the needs of the industry. A second method is for airport organizations to develop and deliver better internal education and training programs. A third method is to develop and provide better external education and training programs through workshops, seminars, conferences, and other programs.

Of the three, the first method of revising curriculum content would appear to have the best overall return for the investment. More individuals would be exposed to a standard that meets the industry need and the cost of implementation will not be a burden on airports. Hiring cost to organizations would be reduced because new hires would require less internal or external training and resources. The second method, that of increased internal airport training, suffers from a concern for available financial and personnel resources (given the nature of many airport budgets), organizational structures, and airport ownership. External training and education derived from workshops, seminars, and similar outreach efforts provide a valuable service but generally require greater allocation of financial resources and suffer from infrequency or a paucity of offering.

\section{SUMMARY}

A primary goal of an academic program is to prepare an individual for his or her chosen career. Knowing what needs to be taught in a curriculum is crucial to that preparation. However, little data has existed to guide advisory groups and educators in the development of curriculum for aviation management programs, and airport management programs in particular.

This paper compares the knowledge and topic areas deemed important by individuals employed in airfield operations positions with the same knowledge and topic areas perceived to 
be possessed by applicants or new hires for similar positions. The data indicate that there are variances among many important topic areas, leading to the conclusion that schools are not properly preparing individuals for airport positions. The data presented in this study can be used to identify course content and learning outcomes for a program focusing on airport management. Written comments from individuals in the field further support the need to bridge the knowledge gap.

The author presents three methods to address the gaps in knowledge: (1) revise university and college curriculum content to focus on learning outcomes that meet the needs of the industry; (2) have airport organizations develop and deliver better internal education and training programs: and (3) develop better external education and training programs through professional organizations, trainers, and outreach organizations. In this author's opinion, the most effective method for addressing the differences noted in the study is through revision of college and university curriculum. 


\section{REFERENCES}

Council on Aviation Accreditation. (2003, July). Accreditation standards manual, Form 101. Auburn, AL.

Flouris, T., \& Gibson, B. (2002). Aviation management job placement: The 2002 perspective. Collegiate Aviation Review, 20(1), 29-48.

Kaps, R.W., \& NewMyer, D.A. (2001). Arriving at consensus: Airport/aviation administration advice provided to airport managers by state aeronautic agencies. Journal of Aviation/Aerospace Education and Research, 11(1) 46-56.

Prather, C.D. (1999). Airport internships: Effectively structuring a departmental rotation internship. Collegiate Aviation Review, 17(1), 53-73.

Prather, C.D. (2006). [Survey of texts used in aviation management programs at CAA accredited universities]. Unpublished raw data.

Phillips, E.D. (2004). A critique of aviation management programs. Collegiate Aviation Review, 22(1), 39-56.

Quilty, S.M. (1996). Educational course and curriculum needs for corporate aviation managers. Journal of Aviation/Aerospace Education and Research, 7(1)21-31.

Quilty, S.M. (2004). Airport Management Program and Curriculum Issues at 2- and 4-year Aviation Colleges and Universities. Collegiate Aviation Review, 22(1) 57-70.

Quilty, S.M. (2005a). Study results on knowledge requirements for entry-level airport operations and management personnel. Journal of Air Transportation ${ }_{2}$ 10(3), 100-122.

Quilty, S.M. (2005b). Skill and trait identification of entry-level airport operations and management personnel. International Journal of Applied Aviation Studies, 5(1), 183-194.

U.S. Department of Transportation. (2004). FAA report to congress: National plan of integrated airport systems 2005-2009. Washington, D.C: U.S. Government Printing Office. 


\section{APPENDIX A}

Matched pair t-tests comparing survey responses of airport manager's requirements (left column) versus perceived new hire's actual knowledge (right column).

\begin{tabular}{|c|c|c|c|c|c|c|}
\hline Rank & Topic & $n$ & $M^{(2)}$ & $S D$ & $t^{(3)}$ & $p^{(4)}$ \\
\hline 2 & Knowledge of airport self-inspection components and techniques. & 106 & -1.89 & 1.11 & -17.27 & $\mathrm{~L}$ \\
\hline 4 & Understanding of the Airport Emergency Plan (AEP) \& response capabilities. & 105 & -1.88 & 1.12 & -17.24 & $\mathrm{~L}$ \\
\hline 3 & Knowledge of airfield lighting, signs \& marking requirements \& maintenance. & 106 & -1.81 & 1.18 & -15.70 & $\mathrm{~L}$ \\
\hline 7 & Knowledge of Airport Certification Manual Requirements and Contents. & 106 & -1.79 & 1.21 & -15.27 & $\mathrm{~L}$ \\
\hline 10 & Knowledge of airport construction activity monitoring and practices. & 105 & -1.79 & 1.28 & -14.38 & $\mathrm{~L}$ \\
\hline 5 & Knowledge of airport condition reporting and issuance of NOTAMs. & 105 & -1.87 & 1.37 & -13.93 & $\mathrm{~L}$ \\
\hline 1 & Knowledge of ground vehicle operation and radio procedures. & 106 & -1.63 & 1.23 & -13.67 & $\mathrm{~L}$ \\
\hline 12 & Knowledge of airport security plan responsibilities under TSA Part 1542. & 105 & -1.70 & 1.29 & -13.50 & $\mathrm{~L}$ \\
\hline 27 & Knowledge of airfield construction methods and processes. & 106 & -1.49 & 1.15 & -13.36 & $\mathrm{~L}$ \\
\hline 9 & Knowledge of SIDA, access control, and identification procedures. & 105 & -1.64 & 1.26 & -13.36 & $\mathrm{~L}$ \\
\hline 11 & Knowledge of wildlife hazard mitigation problems and techniques. & 105 & -1.71 & 1.37 & -12.73 & $\mathrm{~L}$ \\
\hline 13 & Knowledge of 14 CFR Part 77 Objects Affecting Navigable Airspace. & 105 & -1.45 & 1.18 & -12.52 & $\mathrm{~L}$ \\
\hline 17 & Knowledge of Aircraft Rescue/Firefighting techniques and application. & 105 & -1.38 & 1.20 & -11.75 & $\mathrm{~L}$ \\
\hline 18 & Knowledge of fueling operations and fuel storage tanks/trucks safety. & 105 & -1.37 & 1.22 & -11.53 & $\mathrm{~L}$ \\
\hline 22 & Knowledge of FAA Form 5010. & 102 & -1.43 & 1.31 & -10.98 & $\mathrm{~L}$ \\
\hline 14 & Understanding of airport design and layout. & 106 & -1.36 & 1.30 & -10.73 & $\mathrm{~L}$ \\
\hline 8 & Understanding of acronyms, terms, common phrases used in airports. & 105 & -1.22 & 1.17 & -10.69 & $\mathrm{~L}$ \\
\hline 21 & Understanding of a Communications Center function and operation. & 105 & -1.23 & 1.20 & -10.53 & $\mathrm{~L}$ \\
\hline 37 & Knowledge of Environmental Acts, compliance and audits affecting airports. & 105 & -1.06 & 1.05 & -10.27 & $\mathrm{~L}$ \\
\hline 26 & Use of FAA Form 7460-1 Notice of Construction and/or Alteration. & 105 & -1.29 & 1.28 & -10.26 & $\mathrm{~L}$ \\
\hline 23 & Knowledge of Snow and Ice Control Plans and snow removal operations. & 103 & -1.46 & 1.44 & -10.26 & $\mathrm{~L}$ \\
\hline 20 & Knowledge of federal regulatory and enforcement process. & 105 & -1.15 & 1.21 & -9.76 & $\mathrm{~L}$ \\
\hline 49 & Understanding of project management practices. & 106 & -1.09 & 1.16 & -9.72 & $\mathrm{~L}$ \\
\hline 32 & Knowledge of air cargo security plan requirements under TSA Part 1546. & 105 & -1.19 & 1.26 & -9.71 & $\mathrm{~L}$ \\
\hline 28 & Knowledge of air carrier security plan requirements under TSA Part 1544. & 105 & -1.18 & 1.27 & -9.53 & $\mathrm{~L}$ \\
\hline 59 & Understanding of contract and lease administration. & 105 & -0.93 & 1.04 & -9.19 & $\mathrm{~L}$ \\
\hline 42 & Understanding application \& use of pavement deice \& anti-ice compounds. & 102 & -1.25 & 1.38 & -9.10 & L \\
\hline 16 & Knowledge of air traffic control operations and procedures. & 105 & -1.02 & 1.15 & -9.07 & $\mathrm{~L}$ \\
\hline 45 & Understanding of police and law enforcement procedures. & 105 & -0.99 & 1.13 & -8.98 & L \\
\hline 39 & Knowledge of 14 CFR Part 1520 Security disclosure requirements. & 101 & -1.25 & 1.40 & -8.94 & $\mathrm{~L}$ \\
\hline
\end{tabular}


54 Knowledge of bid specifications related to equipment and other purchases.

40 Understanding of environmental laws and regulations.

$\begin{array}{lllll}105 & -0.90 & 1.03 & -8.93 \quad L\end{array}$

44 Knowledge of OSHA regulations and insurance requirements.

$\begin{array}{lllll}105 & -0.90 & 1.03 & -8.93 \quad L\end{array}$

31 Knowledge of new security technology and its application on airports.

$\begin{array}{lllll}105 & -0.92 & 1.07 & -8.84 \quad L\end{array}$

24 Knowledge and understanding of Airline operations and regulations.

$\begin{array}{lllll}105 & -1.02 & 1.23 & -8.47 \quad L\end{array}$

19 Knowledge of aircraft operations and regulations.

$\begin{array}{lllll}106 & -0.92 & 1.11 & -8.46 \quad L\end{array}$

38 Knowledge of DOT hazardous substances, materials, markings \& placards.

$\begin{array}{lllll}105 & -0.84 & 1.03 & -8.34 \quad L\end{array}$

34 Knowledge of material data safety sheet information.

33 Understanding of public relations and information dissemination.

46 Understanding of noise, noise measurement \& laws related to aviation noise.

$\begin{array}{lllll}105 & -0.94 & 1.18 & -8.22 \quad L\end{array}$

$\begin{array}{lllll}104 & -0.97 & 1.23 & -8.02 \quad L\end{array}$

$\begin{array}{lllll}105 & -0.87 & 1.11 & -8.00 \quad L\end{array}$

6 Knowledge of 14 CFR Part 139 requirements and airfield responsibilities.

$\begin{array}{lllll}105 & -0.83 & 1.09 & -7.81 \quad L\end{array}$

61 Knowledge of facility maintenance methods and processes.

$\begin{array}{lllll}106 & -0.91 & 1.40 & -7.72 \quad \mathrm{~L}\end{array}$

29 Knowledge of air traffic navigational equipment and operation.

$\begin{array}{lllll}106 & -0.91 & 1.40 & -7.72 \quad L\end{array}$

$\begin{array}{lllll}106 & -0.83 & 1.12 & -7.65 \quad L\end{array}$

15 Knowledge and understanding of general aviation operations \& regulations.

$\begin{array}{lllll}105 & -0.83 & 1.11 & -7.63 \quad L\end{array}$

25 Understanding of general supervision and management principles.

$\begin{array}{lllll}105 & -0.89 & 1.20 & -7.59 \quad L\end{array}$

68 Understanding of risk management and insurance administration.

$\begin{array}{lllll}105 & -0.78 & 1.11 & -7.21 \quad \mathrm{~L}\end{array}$

72 Understanding of property and real estate management.

$\begin{array}{lllll}105 & -0.79 & 1.17 & -6.95 \quad L\end{array}$

36 Knowledge and understanding of Air taxi/Charter operations \& regulations.

$\begin{array}{lllll}105 & -0.61 & 0.95 & -6.61 \quad L\end{array}$

41 Knowledge of airport/public administration principles and practices.

$\begin{array}{lllll}106 & -0.72 & 1.15 & -6.40 \quad \mathrm{~L}\end{array}$

43 Knowledge \& understanding of Air Cargo/Freight operations, regs., logistics.

$\begin{array}{lllll}104 & -0.72 & 1.17 & -6.29 \quad \mathrm{~L}\end{array}$

63 Understanding of airport and transportation master planning processes.

$\begin{array}{lllll}106 & -0.71 & 1.17 & -6.22 \quad L\end{array}$

65 Knowledge of requirements and procedures for airlines/aircraft deicing.

$\begin{array}{lllll}105 & -0.64 & 1.10 & -5.93 \quad L\end{array}$

47 Understanding of airport capacity, delay and transportation impacts.

$\begin{array}{lllll}102 & -0.79 & 1.37 & -5.84 \quad L\end{array}$

50 Knowledge of human resource and employee development processes.

$\begin{array}{lllll}105 & -0.68 & 1.21 & -5.71 \quad L\end{array}$

75 Knowledge of building construction codes, methods and processes.

$\begin{array}{lllll}105 & -0.53 & 1.02 & -5.36 \quad L\end{array}$

73 Understanding of basic electricity and electronic and application at airports.

$\begin{array}{lllll}105 & -0.59 & 1.16 & -5.19 \quad \mathrm{~L}\end{array}$

35 Knowledge of interpersonal, group and organizational communication.

$\begin{array}{lllll}106 & -0.61 & 1.22 & -5.19 \quad L\end{array}$

55 Understanding of ground transport (taxis, buses, shuttles, etc.) operations.

$\begin{array}{lllll}105 & -0.46 & 0.97 & -4.82 \quad L\end{array}$

78 Knowledge of building system operation (heat, air, utilities, plumbing).

$\begin{array}{lllll}106 & -0.62 & 1.38 & -4.63 \quad L\end{array}$

64 Understanding of parking garage/lot function and operations.

$\begin{array}{lllll}106 & -0.49 & 1.14 & -4.39 \quad L\end{array}$

53 Knowledge of military operations and activity on airports.

$\begin{array}{lllll}105 & -0.54 & 1.27 & -4.38 \quad L\end{array}$

57 Knowledge of new technology development and application at airports.

$105 \quad-0.50 \quad 1.20 \quad-4.25 \quad L$

$\begin{array}{lllll}105 & -0.49 & 1.21 & -4.11 \quad L\end{array}$

60 Understanding of aviation law application to airports and aircraft operations.

71 Knowledge of finance and capital funding methods and processes.

$\begin{array}{lllll}104 & -0.42 & 1.09 & -3.94 \quad L\end{array}$

77 Knowledge of helicopter \& VISTOL operations.

$\begin{array}{lllll}106 & -0.45 & 1.19 & -3.92 \quad L\end{array}$

$\begin{array}{lllll}105 & -0.37 & 1.12 & -3.40 \quad L\end{array}$ 


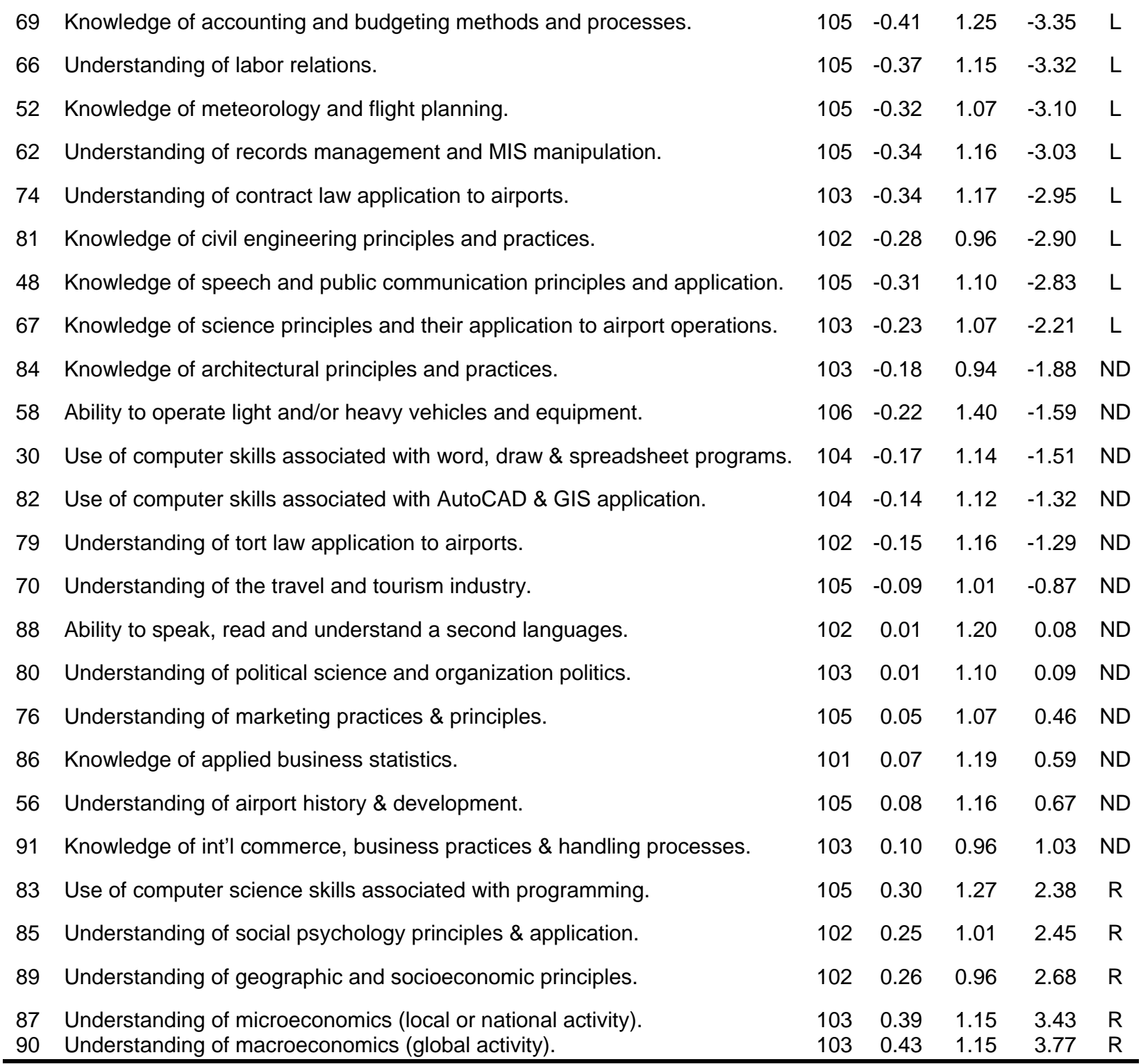

Notes:

${ }^{1}$ Ranking of knowledge topics according to Quilty’s study (2005).

${ }^{2}$ Mean of the means analysis for the two columns.

${ }^{3} t$-value based on degree of freedom $(d f=n-1)$.

${ }^{4} p>0.05$. $\mathrm{L}=$ left column greater than right column. $\mathrm{R}=$ right column greater than left column. $\mathrm{ND}=$ no significant difference. 


\title{
APPENDIX B
}

Comments from airport managers and operations personnel

\begin{abstract}
"Management theories, statistics, and economics are not useful topics at all. Course for airport operations management should be geared toward construction techniques and management, problem solving, conflict resolution, airport documents, Microsoft access, snow removal management, etc.”
\end{abstract}

"Training support used to be strong, [ but] now only what is required [is accomplished] due to financial constraints. Knowing what is [a] hazard to safety is part of knowing right from wrong. Must be knowledgeable about a variety of systems, regulations, etc., as we are routinely required to make decisions that have potentially large impact if wrong decision is made. We don't expect new hires to be expert in anything. Through team approach to everyday work we can carry that individual and don't expect them to be at the level of expertise needed for 1-2 years after hiring."

“Our experience has been that 'operational new hires’ need a lot of training.”

"New hires are typically trained on the job and have no prior experience.”

"New hires (no experience) require 2 years on the job training as a rule."

"This is a great study. I hope these results will help you fill in the gaps between skills and knowledge required and what isn't being taught today."

"Larger airports with larger population draw (experience and education) will provide a better candidate base. Small town airports (non-hub/GA) see more candidates from labor based pool or municipal interdepartmental transfer (city/county). More extensive post employment training required.”

"Very comprehensive! If new hires have had an internship they are much more prepared for success and will reflect different ratings. My scores were based on hiring some one with prerequisite experience.”

"Programs need to put more emphasis on operational subjects and less on management.”

"I assume you are asking about new hires/applicants without actual experience, except maybe an internship. My answers are based on this assumption. I don't believe that anyone can be well prepared (and on most items adequately prepared) until they have some OJT and experience.”

"Answers are based on our experience operating several GA airports. We tend to hire those with no experience and little formal aviation training /education.”

"The role of ops varies widely from airport to airport. Needed knowledge/skills depend on the level of support. At [medium-sized airport], ops officers are solo and are top level management (nights \& weekends). Most of our staff has over 10 years experience. Maturity is very important. Lots of gray areas.”

"Most of the items listed are not taught in school, [instead are] learned on the job. Depending on the airport, many items are not [a] significant part of an ops position (i.e., economics, labor relations).”

"Most items require the hands-on experience to go into the job well prepared. If they have the general book/academic knowledge of each area, then when entering a position the information can be applied to real world situations.” 
"It is the application process that I learned the most. I read the material in class, but until I actually apply it, it doesn’t click. Internships are a must! I learned a great deal at my internships.”

"Pilots are much more experienced and prepared in the AOA due to experience with ATC procedures. Much more emphasis should be placed on condition reporting (NOTAMS, snow ops, etc.) and selfinspection, to prepare students for daily job duties.”

"I have not hired any trained airport operation employees."

"Having common sense is an important strength to have in airport operations. Not only knowing what regulations say, but being able to apply it in a real-world environment. Classes that helped me best in this area are classes that challenged my analytical skills, finance, for example. Being able to assess a situation is extremely important.”

"[This] municipal is a GA reliever for [a medium-hub airport]. Operational personnel cover a wide range of activities from physical labor to administrative projects."

"We wear many different hats - security, landscaper, janitor, sweeper and park aircraft. NOTE: We love what we do!”

"Most new hire or applicants are not prepared because of poor college courses specifically on Part 139 and airport management.”

“A college program should require AAAE written test leading to a CM prior to awarding a degree. Importance of professional organizations like AAAE and state aviation associations should be emphasized."

"Since [this airport] is a small primary airport, very few new hires/applicants are processed. With such a small population to draw conclusions from, response regarding their preparation was not submitted.”

"[A large-hub airport] is an airport that is compartmentalized in every way. Unfortunately, operations employees are exposed only to the airfield and its environment. Ops employees are not exposed to finance, master planning, engineering, etc.”

“The training or right column is a function of each individual's skills, experience, and training/education. As a result, it varies greatly from individual to individual. Our training is based on each individual's needs.” 